\title{
Streptococcus mutans Level Estimation in Saliva Before and After Consumption of Chewable Probiotics among School Children
}

INTRODUCTION: The World Health Organization (WHO) deemed probiotics to be the next most important immune defence system. Also known as the "friendly bacteria", these lactobacilli-derived food supplements are the current trending weapons to fight against Streptococcus mutans, the prime causative organism for dental caries.

AIM: To compare the levels of salivary mutans streptococci in children before and after short-term consumption of dental probiotic chewable containing Lactobacillus acidophilus and Streptococcus salivarius M18.

MATERIALS AND METHOD: A cross-sectional study was performed on 10 healthy subjects in the age group of 6-12 years who were followed for 7 days. The assessment of S. mutans in saliva was done at baseline, 1 hour after consumption of probiotic chewable and after 7 -day of intervention period using mitis salivarius bacitracin agar. The colonies of S. mutans were identified and counted using a digital colony counter.

RESULTS: A statistically significant reduction of salivary S. mutans was recorded after consumption of the probiotic chewable on the $7^{\text {th }}$ day in the probiotic group. Results were found to be statistically significant $(P \leq 0.05)$ when the differences in the reduction of mutans streptococci counts with probiotic chewable and plain chewable on the $7^{\text {th }}$ day were compared.

CONCLUSION: The following study, based on its observations, does conclude that short term consumption of probiotic chewable displays a significant reduction in the level of salivary Streptococcus mutans in children. Thus, keeping in mind the idea that prevention is always better than cure, the awareness regarding probiotics as a therapy to prevent dental caries should be made among both dental practitioners, especially paediatric dentists as well as parents.

KEYWORDS: Probiotics, Lactobacillus Acidophilus, Streptococcus Salivarius, Streptococcus Mutans, Saliva

\section{INTRODUCTION}

We are living in the $21^{\text {st }}$ century where the ultimate pursuit is to seek changes that enhance our health status thereby improving our life from all aspects.

The invention of antibiotics was one among the foremost pathbreaking breakthrough in the world of drugs that resulted miraculous increase in expectancy of life. This greatly improved the standard of human life by decreasing the fatality rate globally. However, the most important drawback with antibiotics was that besides killing harmful bacteria it also kills useful bacteria and hence disturbs the ecosystem of the body, leading to adverse effects like super-infection and drug resistance. This is the point where the dawn of the probiotics transpire that comes with the agenda of 'save more, destroy less.' ${ }^{1}$

"Probiotic," are mechanisms that are employed to selectively remove only the pathogen while leaving the remaining of the oral ecosystem intact. ${ }^{1}$

In 1965, Lilly and Stillwell first coined the term 'Probiotic' which was derived from Greek word- 'Pro' (means 'for') and 'bios' (means life). ${ }^{2}$ Ukrainian born Nobel Prize laureate, Elie Metchnikoff, observed the positive beneficial effect of some bacteria on human health and suggested that these beneficial bacteria may be used to replace harmful microbes within the body. ${ }^{2}$ The WHO/Food and Agriculture Organization defines probiotics as: "Live micro-organisms, which when administered in adequate amounts, confer a healthbenefit on the host". 3

Streptococcus mutans has been regarded as one of the foremost and most virulent of the dental caries producing microorganisms. They form colonies and initiate plaque formation on the tooth surface by their ability to synthesize extracellular polysaccharides from sucrose, mainly water-soluble glucan, with the assistance of the enzyme glucosyltransferase. It's believed that inhibition of the colonization of $S$. mutans on tooth surface prevents the formation of dental plaque which successively lowers the probabilities of caries. ${ }^{4}$ Probiotics attaches themselves to dental tissues to determine a cariostatic effect and thus become a component of the bio-film to fight the cariogenic 


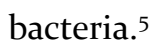

Dental caries is one among the foremost common yet preventable dental disease that's prevalent in childhood and also affects an individual throughout its lifetime. A number of recent approaches for prevention of dental caries include chemo prophylactic agents, caries vaccine, sugar substitutes, fluoride, antibiotics, bacteriotherapy, or replacement therapy. ${ }^{6}$

Probiotics also play a crucial role in the prevention and treatment of assorted gastrointestinal disorders, like diarrheal diseases, irritable bowel syndrome, Helicobacter pylori-induced gastritis and atopic diseases. ${ }^{7}$ They also possess biological potential in the management of intra oral halitosis. ${ }^{8}$

The probiotic strains that are most commonly available are Lactobacillus and Bifidobacterium species. Bacterial strains that have displayed probiotic action within the mouth include lactobacilli species (Lactobacillus acidophilus, Lactobacillus rhamnosus GG, Lactobacillus johnsonii, Lactobacillus rhamnosus, Lactobacillus reuter, Lactobacillus gasseri, Lactobacillus casei, Lactobacillus paracasei), Bifidobacterium species (Bifidobacterium longum, Bifidobacterium infantis, Bifidobacterium bifidum, Bifidobacterium animalis strain DN-173 010), and et al. (Streptococcus salivarius, Weissella cibaria). ${ }^{9}$

Dairy products like milk, yogurt, and cheese are commonly selected as delivery vehicles for the selected bacteria. Probiotics may be delivered by lozenges, powder, gelatine, straw or tablets. However, the simplest and most efficient vehicle for probiotic delivery is yet to be identified. ${ }^{10}$

The present clinical study was conducted to investigate whether short term consumption of chewable tablets containing L.acidophilus and S.salivarius M18 probiotics can affect the levels of salivary S. mutans count in school children, thus determining the efficacy of probiotics as the new generation weapon against combating dental caries.

\section{MATERIALS AND METHOD}

The present study was a randomized placebocontrolled design performed in New Lyceum Children Academy, Chandwaji, Jaipur, Rajasthan, India. The study protocol was in accordance with the approved guidelines of the Institutional Ethical Committee of
NIMS University. Consent forms were signed by school authorities prior to subject enrolment in the study. This study compares S. mutans levels in saliva before and after consumption of chewables containing probiotic.

Inclusion criteria included children in the age group of 6-12 years, all healthy children with no history of consumption of antibiotics or probiotics preceding 1 month, no clinically detectable caries and those having no history of undergoing any preventive dental treatment, while the presence of any mental disorders, chronic debilitating diseases, congenital or systemic disorders, children undergoing orthodontic treatment ${ }^{6}$ and not willing to participate in the study were excluded from the study.

The study group comprised of 10 healthy school children between the age group of 6-12 years of age randomly selected from Lyceum Primary School, Jaipur. Five of these volunteers posed as study subjects (subjects 1-5) and five as controls (subjects A to E). Subjects 1 to 5 were daily provided with one probiotic chewable (Nature's Plus Animal Parade Children's Chewable Tooth Fairy Probiotic) and subjects A to E were daily provided with one placebo chewable (Super Gummy Calcium plus vitamin D chewable supplement) respectively for 7 days.

The administered probiotic chewable has the composition - xylitol (2g), vitamin $\mathrm{D}_{3}$ (40oIU), Calcium (as amino acid chelate/complex-30omg), Lactobacilli acidophilus (2 billion Viable cells-15omg) and S.salivarius M18 (1omg).

The administered placebo chewable has the composition- tricalcium phosphate and vitamin D2.

Samples of stimulated whole saliva were collected after a clinical examination, immediately before and 1 hour after sucking for 7 days. The daily sucking was performed for 10 minutes in the morning.

After the sucking, the participants were made comfortable and asked to swallow pre-existing saliva so as to clear the mouth of any residual saliva. The saliva was collected directly in a sterile plastic previously coded container.

The collected samples were stored in room temperature $\left(17^{\circ} \mathrm{C}-25^{\circ} \mathrm{C}\right)$. All the samples were sent to AGSS Analytical and Research Laboratory Pvt. Ltd, New Delhi 
on the $7^{\text {th }}$ day in dry ice boxes.

The samples were precoded. The laboratory clinicians and technicians evaluating the culture plates were blinded to the subject's group assignment.

Assessment of saliva was done at baseline, after 1 hour and on the $7^{\text {th }}$ day.

Laboratory Procedure: To explain the procedures for detection / enumeration of S. mutans.

Culture Media: This included phosphate buffer saline, Mitis-Salivarius agar (MSA), Todd Hewitt medium, Nutrient - agar, reagent for gram's staining, blood agar and bile aesculin agar.

Reagents: These were crystal violet solution, gram's iodine, ethyl alcohol $70 \%$ and safranine.

Procedure: (i) For detection: This was done by taking a specific quality of test sample (1 gm) in phosphate buffer saline $(9 \mathrm{ml})$ (e.g. one part of test sample to nine part of phosphate buffer solution) and mixed. It was then incubated at $37^{\circ} \mathrm{C}$ for 24 hours. After 24 hours, $1 \mathrm{ml}$ sample on Mitis-salivarius agar (MSA) was spread and incubated at $30^{\circ} \mathrm{C}$ overnight. Blue colour colonies were observed (S.mitis, Salivarius, S.mutans). After overnight growth in microaerophilic condition (Candle jar), bacterial colonies were picked from MSA plate and cultured on Todd-Hewitt medium, opaque colonies were observed.

(ii) For confirmation: The following tests were taken: gram staining: gram positive cocci, catalase test: bubble formation was not observed hence oxygen was not released so it gave a negative catalase test, haemolysis on blood agar plate: it showed gamma haemolysis., growth on bile esculin agar: no growth, bacitracin resistance: growth observed and arginine hydrolysis: no zone of hydrolysis observed.

Streptococcus mutans in saliva of all the participants was determined by using a colony counter and the number of colony forming units was counted. Microbial counts were expressed as colony-forming units per $\mathrm{ml}$ of saliva. ${ }^{11}$

Statistical Analysis: This was performed using SPSS version 22 (IBM Corporation). The mean and standard deviation for Streptococcus mutans count in samples were determined using descriptive statistics and comparative analysis between study and control group was done by unpaired t-test (Student's t test). The level of significance was set at $\mathrm{p} \leq 0.05$.

\section{RESULTS}

In this clinical study, the mean salivary Streptococcus mutans count was measured at three different time phases, i.e. at baseline, after 1 hour and on $7^{\text {th }}$ day. At baseline the mean salivary Streptococcus mutans count was, for post consumption probiotic chewable (study group) and plain vitamin D chewable (control group), $200.4( \pm 7.79)$ and 197.4 $( \pm 7.60)$; after 1 hour, 193.8 $( \pm 8.22)$ and $204( \pm 5.56)$; and on $7^{\text {th }}$ day, $37.6( \pm 10.83)$ and $195.2( \pm 10.70)$, respectively. (Figure 1)

It was observed that, the comparison between study and control group of the mean salivary $\mathrm{S}$. mutans count was statistically significant $\left(\mathrm{p}<0.000^{*}\right)$ on $7^{\text {th }}$ day (Table 1).

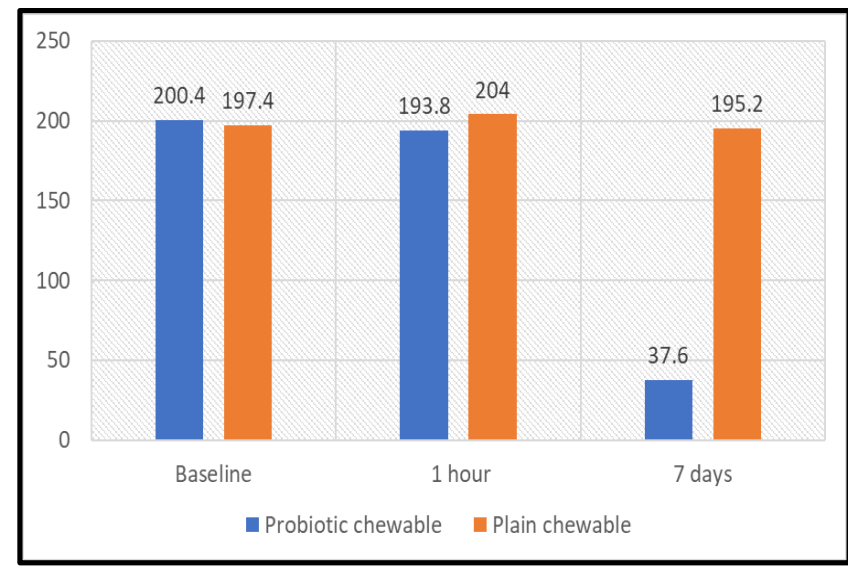

Figure 1. Progressive Decline in The Levels of Streptococcus Mutans at Baseline, 1 hour and after 7 Days of Dental Probiotic Chewable Consumption which was Statistically Significant.

\section{DISCUSSION}

Probiotic technology presents with a breakthrough approach for the upkeep of oral health by using natural beneficial bacteria that are commonly found in healthy oral cavities so as to produce natural defence against those harmful bacteria posing as a threat to the dentition and therefore the surrounding structures. The oral ecology is benefitted by probiotics which cause prevention of the adherence of other bacteria and also alters the protein composition of salivary pellicle. ${ }^{4}$

Grover and Luthra ${ }^{12}$ (2011) reported various direct and indirect means in support of the hypothetical mechanism of probiotic action in mouth. The direct 


\begin{tabular}{|c|c|c|c|c|c|c|c|c|c|}
\hline & \multirow[t]{2}{*}{ Group } & \multirow[t]{2}{*}{$\mathbf{n}$} & \multirow[t]{2}{*}{ Mean } & \multirow[t]{2}{*}{$\begin{array}{c}\text { Std. } \\
\text { Deviation }\end{array}$} & \multirow[t]{2}{*}{$\begin{array}{l}\text { Std. } \\
\text { Error } \\
\text { Mean }\end{array}$} & \multicolumn{2}{|c|}{$\begin{array}{l}95 \% \text { Confidence } \\
\text { Interval of the } \\
\text { Difference }\end{array}$} & \multirow[t]{2}{*}{$\mathbf{t}$} & \multirow[t]{2}{*}{ p value } \\
\hline & & & & & & Lower & Upper & & \\
\hline \multirow[t]{2}{*}{ Baseline } & Study & 5 & 200.4000 & $7 \cdot 79744$ & 3.48712 & \multirow[t]{2}{*}{-8.23097} & \multirow[t]{2}{*}{14.23097} & \multirow[t]{2}{*}{0.616} & \multirow[t]{2}{*}{0.555} \\
\hline & Control & 5 & $197 \cdot 4000$ & 7.60263 & 3.40000 & & & & \\
\hline \multirow{2}{*}{$\begin{array}{l}\text { After } 1 \\
\text { hour }\end{array}$} & Study & 5 & 193.8000 & 8.22800 & 3.67967 & \multirow[t]{2}{*}{-20.44551} & \multirow[t]{2}{*}{0.04551} & \multirow[t]{2}{*}{-2.296} & \multirow[t]{2}{*}{0.051} \\
\hline & Control & 5 & 204.0000 & $5 \cdot 56776$ & 2.48998 & & & & \\
\hline \multirow{2}{*}{$\begin{array}{c}\text { After } 7 \\
\text { days }\end{array}$} & Study & 5 & 37.6000 & 10.83051 & 4.84355 & \multirow{2}{*}{$\begin{array}{c}- \\
173.30793\end{array}$} & \multirow{2}{*}{$\begin{array}{c}- \\
141.89207\end{array}$} & \multirow[t]{2}{*}{-23.136} & \multirow[t]{2}{*}{$0.000^{*}$} \\
\hline & Control & 5 & 195.2000 & 10.70981 & 4.78957 & & & & \\
\hline
\end{tabular}

Table 1. Streptococcus mutans Level Estimation in Saliva before and after Consumption of Chewable Probiotics among School Children

interactions in dental bacterial plaque includes binding of oral microorganisms to protein, production of chemicals that inhibits oral bacteria, action on plaque formation and its complex ecosystem by competing and intervening with bacterial attachments. Several indirect probiotic actions are modulation of systemic immune function, enhances local immunity, regulates mucosal permeability and effects on the non-immunologic defence. It also functions as antioxidants and neutralizes free electrons thus prevents plaque formation.

Probiotics lower the $\mathrm{pH}$ in order that microorganism cannot form bacterial plaque and calculus that causes oral inflammation. ${ }^{13}$ The present study has tried to work out the effect of probiotic on salivary oral microflora. The commercially available probiotic product that has been used for this clinical study purpose consistspredominantly of Lactobacillus acidophilus and Streptococcus salivarius M 18.

Hatakka $\mathrm{K}$ et al. were the primary ones to report a dietary Lactobacillus strain, L. rhamnosus GG on its caries inhibiting ability in vivo. The probiotic milk used in their study showed a moderate tendency to decrease S. mutans levels, which were semiquantitatively detected in a pooled saliva-plaque sample employing a diagnostic test. ${ }^{14}$

Di Pierro $\mathrm{F}$ et al. performed a clinical study using probiotic containing salivarius $\mathrm{M} 15$ and concluded that after 90 days of treatment with this oral probiotic, it has increased the probabilities of avoiding new cavities in children. This outcome is taken into account thanks to the precise anticariogenic characteristics of strain $\mathrm{M}_{18}$ that, after colonizing the oral mucosa, is able to release bacteriocins, limiting the growth of $S$. mutans and $S$. sobrinus, and therefore the enzymes dextranase and urease, catalysing the breakdown of dextran (aiding solubilization of plaque) and the hydrolysis of urea (increasing saliva $\mathrm{pH}) .{ }^{15}$

Sudha et al. ${ }^{16}$ conducted study on 5-13 years age group which showed higher prevalence of decay in 5-7 years age group compared to that of 8-9 and 11-13-years age group. In our study, children of 6-12 years were selected as at this age the permanent teeth are erupting, so the chances of the new surfaces being colonized by pathogenic bacteria would be greater. Therefore, it might be helpful in long run to implement preventive measures during this age range. ${ }^{16}$

Various studies have been carried out in India to evaluate and validate the beneficial effect of probiotic milk, curd and ice-creams on the oral ecology. However, not many studies have been performed using

commercially available children's chewable dental probiotics. Therefore, our study was done to estimate the effect of one such commercially available children's chewable dental probiotic on the level of salivary mutans streptococci. Children accepted the given product with ease as it was vanilla flavoured and in shape and form of animals that suited well with their taste.

In the present clinical study, on comparing the mean salivary mutans streptococci at baseline, after 1 hour, and after 7 days of consumption of probiotic and plain non-probiotic chewable, the result was found to be statistically significant after 7 days $(P \leq 0.05)$ period. This was in accordance with the study done by Caglar $\mathrm{E}$ et al. $^{10}$ in which the dissolution of probiotics from a lozenge administered medical device has been shown 
to significantly $(\mathrm{P}<0.05)$ reduce salivary mutans streptococci following a 10-day sucking of the test medical device in contrast to the control medical device.

Marked reduction in salivary S. mutans ( $\mathrm{P} \leq 0.05)$ was seen in our clinical study after consumption of dental probiotic chewable that was also in accordance with the study done by Kavitha $\mathrm{M}$ et al. ${ }^{17}$ in which after consumption of probiotic containing lozenge twice daily (once in morning and once in the evening post brushing) for 1 month, when compared to baseline, a significant reduction of salivary $S$. mutans was recorded after 1 month intervention and 6 months follow-up.

Our results were also in accordance to previous studies performed by Chinnappa et al. ${ }^{18}$, Caglar et al. ${ }^{19}$, Cildir SK et al. $^{20}$, Ahola et al. $^{21}$ and Jindal et al. $^{22}$ in which a statistically significant reduction of salivary $\mathrm{S}$. mutans was recorded after probiotic yogurt consumption ( $\mathrm{p} \leq$ 0.05).

Singh et al. ${ }^{23}$ also reported a remarkable statistically significant reduction in mutans streptococci count $(\mathrm{P} \leq$ 0.05) probiotic ice-cream ingestion which is in accordance to the results of the present study. However, our results were in contrast to an earlier study performed by Chuang et al. ${ }^{24}$ which showed no differences in the counts of mutans streptococci between probiotic and control groups.

The decrease in levels of salivary S. mutans in the present study can be considered due to the probable mechanism of action of probiotics that is bacterial adhesion, capability to early colonize in oral cavity, interspecies interaction and immunomodulation.

In the present study, few of the limitations that can be rendered are as follows: firstly, the sample size considered was small. Secondly, the placebo chewable were not identical in form and taste with the probiotics. And lastly, mutans streptococci present in the saliva can only be thought to be an intermediate endpoint for caries. It remains to be investigated whether or not this really is helpful for the patients. ${ }^{9}$

Thus, the current clinical study proves that short term administration of probiotics resulted in significant reduction of cariogenic bacterial count of $\mathrm{S}$. mutans. Prolonged administrations of probiotic preparations may act as a preventive role against caries development. Therefore, long term clinical trials with a larger sample size on effects of children's dental probiotic chewable in inhibiting the bacterial count of S. mutans would be commendable.

\section{CONCLUSION}

Keeping in mind the phrase, "Prevention is better than cure.", the use of probiotic chewable tablets could be implemented for the prevention of dental caries in children. Probiotics help in replacing pathogenic microorganisms by probiotic healthy bacteria, thereby preventing enamel demineralization that ultimately leads to the development of dental caries. The present in-vitro examination showed that commercial probiotics are rather efficient against inhibition of $\mathrm{S}$. mutans. However, more research with a larger sample size and long-term clinical trials is required. It is also important to understand that the efficacy of probiotics proven hence is only against a particular caries causative strain and the thus clinical trials against other caries causing strains and micro-organisms needs to be carried out.

\section{ACKNOWLEDGEMENT}

This study was conducted independently and not sponsored by any outside body. The authors would like to thank all participants for their valuable help and cooperation.

\section{REFERENCES}

1. Dash TR, Verma T, Suvarna M, Ghosh S, Singh N, Pradhan A. Probiotics and Oral Health. Int J Oral Health Med Res 2015;2(2):123-5.

2. Sareen M, Roy S, Singh SK, Gupta A. A review on probiotics and their implications in dentistry. Journal of Dental Sciences 2012;1(2):7-10.

3. Hill C, Guarner F, Reid G, Gibson GR, Merenstein DJ, Bruno Pot, et al. The International Scientific Association for Probiotics and Prebiotics consensus statement on the scope and appropriate use of the term probiotic. Nat Rev Gastroenterol Hepatol. 2014;11(8):506-14.

http://dx.doi.org/10.1038/nrgastro.2014.66.

4. Dhawan R, Dhawan S. Role of probiotics on oral health: A randomized, double-blind, placebocontrolled study. J Interdiscip Dent. 2013; 3:71-8

5. Singh K, Kallali B, Kumar A, Thaker V. Probiotics: A review. Asian Pacific Journal of Tropical Biomedicine 2011;1:S287-S290.

6. Siddiqui M, Singh C, Masih U, Chaudhry K, Hegde DY, Gojanur S. Evaluation of Streptococcus mutans levels in saliva before and after consumption of probiotic milk: A clinical study. J Int Oral Health. 2016;8(2):195-8. 
7. Broekaert IJ, Walker WA. Probiotics and chronic disease. J Clin Gastroenterol. 2006;40:270-4.

8. Allaker RP, Stephen AS. Use of probiotics and oral health. Curr Oral Health Rep. 2017;4:309-18.

9. Bhalla M, Ingle NA, Kaur N, Yadav P. Mutans streptococci estimation in saliva before and after consumption of probiotic curd among school children. J Int Soc Prev Community Dent. 2015;5(1):3134

10. Caglar E, Kuscu OO, Cilder SK, Kuvvetli SS, Sandali $\mathrm{N}$. A probiotic lozenge administered medical device and its effect on salivary mutans streptococci and lactobacilli. Int J Paediatr Dent. 2008;18(1):35-9.

11. Wan AK, Seow WK, Walsh LJ, Bird PS. Comparison of five selective media for the growth and enumeration of Streptococcus mutans. Aust Dent J 2002;47(1):21-6.

12. Grover HS, Luthra S. Probiotics: The nano soldiers of oral health. J Indian Acad Clin Med 2011;13(1): s48-54.

13. Ishihara K, Miyakawa H, Hasegawa A, Takazoe I, Kawai Y. Growth Inhibition of Streptococcus Mutans by Cellular Extracts of Human Intestinal Lactic Acid Bacteria. Infection and Immunity 1985;49692-694.

14. Hatakka K, Savilahti E, Pönkä A, Meurman JH, Poussa T, Näse L, et al. Effect of long term consumption of probiotic milk on infections in children attending day care centers: Double blind, randomised trial. $\mathrm{Br}$ Med J. 2001; 322:1327

15. Di Pierro F, Zanvit A, Nabili P, Risso P, Fornaini C. Cariogram outcome after 90 days of oral treatment with Streptococcus salivarius M18 in children at high risk for dental caries: results of a randomized, controlled study. Clin Cosmet Investig Dent. 2015;7:107-3.

16. Sudha P, Bhasin S, Anegundi RT. Prevalence of dental caries among 5-13-year-old children of Mangalore city. J Indian Soc Pedod Prev Dent. 2005;23(2):74-9.

17. Kavitha M, Prathima G S, Kayalvizhi G, Sanguida A, Ezhumalai G, Ramesh V. Evaluation of Streptococcus mutans serotype e, $\mathrm{f}$ and $\mathrm{k}$ in saliva samples of 6-12year-old school children before and after a short-term daily intake of the probiotic lozenge. J Indian Soc Pedod Prev Dent. 2019; 37:67-74.

18. Chinnappa A, Konde H, Konde S, Raj S, Beena JP. Probiotics for future caries control: A short-term clinical study. Indian J Dent Res. 2013;24(5):547-9.

19. Caglar E, Sandalli N, Twetman S, Kavaloglu S, Ergeneli S, Selvi S. Effect of yogurt with Bifidobacterium DN-173 o10 on salivary mutans streptococci and lactobacilli in young adults. Acta Odontol Scand. 2005;63:317-20.

20. Cildir SK, Germec D, Sandalli N, Ozdemir FI, Arun $\mathrm{T}$, Twetman S, et al. Reduction of salivary mutans streptococci in orthodontic patients during daily consumption of yoghurt containing probiotic bacteria. Eur J Orthod. 2009;31:407-11.

21. Ahola AJ, Yli-Knuuttila H, Suomalainen T, Poussa T, Ahlström A, Meurman JH, et al. Short-term consumption of probiotic-containing cheese and its effect on dental caries risk factors. Arch Oral Biol. 2002;47(11):799-804.

22. Jindal G, Pandey RK, Agarwal J, Singh M. A comparative evaluation of probiotics on salivary mutans streptococci counts in Indian children. Eur Arch Paediatr Dent 2011;12(4):211-5.

23. Singh RP, Damle SG, Chawla A. Salivary mutans streptococci and lactobacilli modulations in young children on consumption of probiotic ice-cream containing Bifidobacterium lactis Bb12 and Lactobacillus acidophilus La5. Acta Odontol Scand. 2011;69(6):389-94.

24. Chuang LC, Huang CS, Ou-Yang LW, Lin SY. Probiotic Lactobacillus paracasei effect on cariogenic bacterial flora. Clin Oral Investig. 2011;15(4):471-6.

\section{AUTHOR AFFILIATIONS: (*Corresponding Author)}

Post-Graduate Student [ORCID: 000o-0003-2857-6901 (Dr. Shinjini Dey)]

Professor and Head

Senior Lecturer

Department of Pedodontics and Preventive Dentistry, NIMS Dental College \& Hospital, Jaipur, Rajasthan, India 